Supporting Information for

\title{
Determination of $\mathrm{p} K_{a}$ Values of Hydrophobic Colorimetric $\mathrm{pH}$ Sensitive Probes in Nanospheres
}

\author{
Xiaojiang Xie*, Jingying Zhai, Zdeňka Jarolímová and Eric Bakker* \\ Department of Inorganic and Analytical Chemistry, University of Geneva, CH1211, Geneva, Switzerland \\ Email: Xiaojiang.Xie@unige.ch, Eric.Bakker@unige.ch
}

Table S1. Amounts of chromoionophore, solvatochromic dyes and ion exchanger used to prepare the nanospheres

\begin{tabular}{|c|}
\hline $0.34 \mathrm{mg}$ of CH I + 0.87 $\mathrm{mg}$ of $\mathrm{Na}^{+} \mathrm{R}^{-}$ \\
\hline $0.47 \mathrm{mg}$ of $\mathrm{CH}$ III $+0.92 \mathrm{mg}$ of $\mathrm{Na}^{+} \mathrm{R}^{-}$ \\
\hline $0.30 \mathrm{mg}$ of $\mathrm{Ox} \mathrm{R}+0.73 \mathrm{mg}$ of $\mathrm{Na}^{+} \mathrm{R}^{-}$ \\
\hline $0.65 \mathrm{mg}$ of $\mathrm{Ox} \mathrm{B}+1.77 \mathrm{mg}$ of $\mathrm{Na}^{+} \mathrm{R}^{-}$ \\
\hline 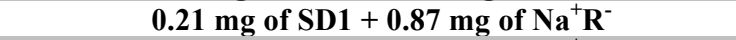 \\
\hline $0.19 \mathrm{mg}$ of SD1 $+1.28 \mathrm{mg}$ of $\mathrm{Na}^{+} \mathrm{R}^{-}$ \\
\hline $0.32 \mathrm{mg}$ of SD2 $+0.84 \mathrm{mg} \mathrm{of} \mathrm{Na}^{+} \mathrm{R}^{-}+1.24 \mathrm{mg}$ of $\mathrm{Ox} \mathrm{R}$ \\
\hline
\end{tabular}

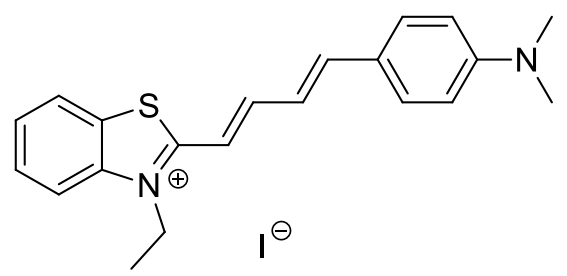

Figure S1. Chemical structure of the solvatochromic dye (SD2).

The measurement of the basicity for the chromoionophores was attempted with a previously reported method used to determine stability constants for optically silent ion-carrier complexes. ${ }^{1}$ For this purpose, the solvatochromic dye and the chromoionophore must exhibit a large spectral separation. Here, Ox R and SD2 were chosen to prepare nanospheres together with $\mathrm{Na}^{+} \mathrm{R}^{-}$. In principle, as the $\mathrm{pH}$ decreases, the emission intensity should decrease because SD2 is exchanged out of the nanospheres to the aqueous solution. Excitation wavelength was chosen at $600 \mathrm{~nm}$ to suppress the emission from protonated Ox R. However, as shown in Figure $\mathrm{S} 2 \mathrm{a}$, some increase in fluorescence due to the protonation of $\mathrm{Ox} \mathrm{R}$ was observed in $\mathrm{pH}$ range from 11.7 to 9.2 , indicating that the two dyes did not match perfectly. Indeed, looking for dye-pairs that exhibit extremely large spectrum separation is not easy since many chromoionophores and solvatochromic dyes have quite broad absorbance and emission bands. Nonetheless, the $\mathrm{pH}$ response of the nanospheres in the range from 8 to 3 was used for the calibration. We assumed that in this $\mathrm{pH}$ range, the fluorescence change was dominated by SD2. The response was then compared with the one from nanospheres containing only SD2 and $\mathrm{Na}^{+} \mathrm{R}^{-}$. After fitting with the theoretical curve, the pKa value of $\mathrm{Ox} \mathrm{R}$ was determined as $6.1 \pm 0.2$. 

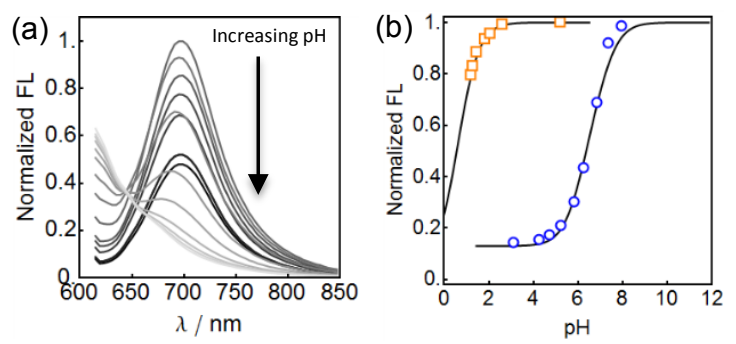

Figure S2. (a) Fluorescence emission spectra of the nanospheres containing $\mathrm{Na}^{+} \mathrm{R}^{-}, \mathrm{SD} 2$ and $\mathrm{Ox} \mathrm{R}$ at various $\mathrm{pH}$. A quenching of fluorescence intensity is observed upon increasing $\mathrm{pH}$. (b) $\mathrm{pH}$ calibrations for the nanospheres containing $\mathrm{Na}^{+} \mathrm{R}^{-}, \mathrm{SD}^{2}$ and $\mathrm{Ox}$ $\mathrm{R}$ (blue circles) and for the nanospheres containing only $\mathrm{Na}^{+} \mathrm{R}^{-}$and $\mathrm{SD} 2$ (orange squares).

The degree of protonation $1-\alpha$; is calculated using the following equation:

$$
1-\alpha=\frac{A-A_{\min }}{A_{\max }-A_{\min }}
$$

where $\mathrm{A}_{\min }$ and $\mathrm{A}_{\max }$ are the minimum and maximum absorbance values measured at $\mathrm{pH} 12$ and $\mathrm{pH} 3$ for nanospheres, respectively.

The derivation of the theoretical response function for the nanospheres containing chromoionophore and ion exchanger and for the nanospheres containing solvatochromic dyes have been described elsewhere ${ }^{2,3}$ and to avoid redundancy, will not be repeated here. To fit the experimental data as shown in Figure 2 (red dashed curves), we have assumed multiple $\mathrm{p} K_{a}$ values for the chromoionophores:

Single $\mathrm{p} K_{a}$ value:

CH I: $\mathrm{K}=8.8$

CH III: $\mathrm{K}=10.2$

Ox R: $\mathrm{K}=7.3$

Ox B: $\mathrm{K}=7.4$

Multiple $\mathrm{p} K_{a}$ values:

CH I: $\mathrm{K}=9.9(50 \%)$ and $7.8(50 \%)$

CH III: $\mathrm{K}=11.8(40 \%)$ and $9.8(40 \%)$ and $7.2(20 \%)$

Ox R: $\mathrm{K}=9.0(1 / 3)$ and $7.0(1 / 3)$ and $5.6(1 / 3)$

Ox B: $\mathrm{K}=9.1(1 / 3)$ and $7.0(1 / 3)$ and $5.5(1 / 3)$

\section{References}

(1) Xie, X.; Bakker, E. Anal. Chem. 2015, 87, 11587.

(2) Bakker, E.; Bühlmann, P.; Pretsch, E. Chem. Rev. 1997, 97, 3083.

(3) Xie, X.; Gutiérrez, A.; Trofimov, V.; Szilagyi, I.; Soldati, T.; Bakker, E. Anal. Chem. 2015, 87, 9954. 